shattered leg - a cruel injury aggravated by irritatingly painful, though mainly superficial, porcupine damage-called for an improvised 'bush' operation, skilfully carried out with meticulous care. The reader is left to judge the wisdom and justification for returning to the wild dangerous carnivores after long and happy association with man.

There is much useful information concerning the care and management of wild animals; the excellent monochrome illustrations are eloquent. An absorbing book which cannot be too highly recommended.

C. R. S. PITMAN

\title{
Lake Chad, by Sylvia K. Sikes. Methuen, £3.95.
}

The author was born in Kenya, educated in England, and since 1947 has worked in various parts of Africa. Four times between 1955 and 1970 she has visited Lake Chad and on the last occasion, sponsored by the Guardian/Eyre and Spottiswoode Exploration Bursary, she took a yacht, the Jolly Hippo.

Chad remains the least known of the great lakes of Africa for it is away from the main lines of communication and difficult to navigate. The water level varies with the rainfall - the average depth is less than $2 \mathrm{~m}$-and it is girt with swamps, shoal waters, floating islands and ancient dune systems. It is well known for its amphibious Yedina people-'pirates of the papyrus' - who make boats of gourds and papyrus bundle rafts, which are comparable with the papyrus rafts of Lake Victoria and the ancient boats of Egypt; their cattle have swollen horns which help them to swim long distances. The abundant fish fauna proves a former water connection right across the southern Sahara. Of these things you will read, but also of much else.

There is a long chapter, for example, on 'the puzzle of the puddle', why Lake Chad has remained fresh while nearly all closed basin lakes are more or less saline; the author's explanation is not very convincing. Chapters on flora and fauna are somewhat uneven, but FPS members will be pleased to read that there are still quite a lot of sitatunga, and the dama gazelle, scimitar-horned oryx and addax are recovering in numbers in the Cameroons sector as a result of strict conservation methods. A proposal is made for a wildlife park along part of the Nigerian lake-shore. The last chapters are devoted to the inevitable modernisation of man, and it is sad to find overfishing and over-grazing recorded-albeit with some careful development by the International Chad Basin Commission.

All in all, Sylvia Sikes becomes a worthy member of that small group of women explorer-naturalists in Africa, of whom not many have focused their attention on lakes and rivers, since the days of Mary Kingsley.

\section{E. B. WORTHINGTON}

\section{Guide to the Freshwater Fishes of Britain and Europe, by} Bent J. Muus and Preben Dahlstrøm. Collins, £2.25.

This attractive book was first published in Danish; in this English translation 130 species are listed, omitting certain endemics from the Caspian and Black Sea basins. A small distribution map accompanies the description of each species. Each fish is illustrated in colour, and a black diamond beside the name indicates that the fish occurs in the British Isles; the diamond is in brackets for introduced species such as rainbow trout.

An introductory section describes various attributes of fishes such as the parts of the body, methods of swimming, etc., and diagrams of vomerine and pharyngeal bones are included among the excellent black, white and brown illustrations. An account of freshwater habitats with their characteristic fish 
species has useful outline diagrams of many of them against a profile of a river and of a lake. The central section begins with a key to the main groups of fishes, based on body shape and on types and arrangements of fins. There are two pages each of text and pictures of important food animals at the beginning; twelve further pages at the end of the section are devoted to crayfish, the mitten crab, the pearl mussel and fish predators and parasites. The 130 species of fish are described in 142 pages with many delightful illustrations, including small colour pictures of principal food items for nearly every fish species and sometimes also colour pictures of young stages, predators, plants or fishing lures. There are keys to the species within large families such as the salmon and carp families. The descriptions of the individual species include information about size, habitat, feeding habits, spawning habits and value to man, if any.

It is a pity that the book is marred by occasional errors, such as, for instance, a confusion of the captions associated with the diagrams of swimbladder arrangements of perch and herring and, more serious, the omission of asterisks in the key to the carp family to indicate that the following species occur in Britain: dace, roach, minnow, bitterling (introduced), bleak, bream and white bream. In spite of these and other mistakes, however, it is highly recommended. The text includes a wealth of information and the illustrations are not only helpful but so beautiful that it is a pleasure simply to thumb through looking at the pictures.

M.E. VARLEY

\section{The Palaearctic-African Bird Migration Systems, by R. E. Moreau. Academic Press, $£ 7.80$.}

This is an important scientific book, and, as it deals with movements and ecology, one with lessons for conservation. It is a posthumous publication, the distinguished author having died in 1970 after devoting the last years of his life, under the handicap of severe illness, to collecting facts for it from a wide spectrum of literature and from numerous correspondents; and all this was based on his own extensive knowledge of African conditions and the native birdlife, subject of an earlier work. Until near the end, his hospital bed was deep in papers as he struggled to complete his task; even so, the book still needed skilful editing by his literary executor, Dr J. F. Monk.

The volume includes a massive presentation of data, species by species, but here it is possible only to highlight a few points in the more general chapters. It is estimated that about 3750 million migrants from the Palaearctic Region spend the northern winter in Africa south of the Sahara, and a major problem is how this vast extra population is supported. The majority do not cross the equator, and their stay in the northern tropics roughly coincides with the dry season and a deteriorating food situation. In the southern tropics, where the seasons are reversed, food is more abundant but there is greater competition by the native birds then breeding.

The migrants come to Africa not only from Europe but also from Asia; in the latter an initially westward flight avoids the barrier of the Tibetan plateau and the Himalayas, which few cross and only a minority circumvent. Even where the movement is mainly southwards, from Europe, there are the formidable barriers of the Mediterranean and the Sahara, sometimes both crossed in a single prodigious flight.

There is increasing evidence of the recurrence of individuals at the same wintering sites in successive years, and also replication of intratropical winter movements; some of these last, incidentally, have the classic form of nocturnal migration. The whole system shows substantial regularity, and yet the history of climatic change requires that the present pattern must have 